Polymer Journal, Vol. 38, No. 9, pp. 989-995 (2006)

(C) 2006 The Society of Polymer Science, Japan

\title{
Molecular Dynamics Simulations of a Main-Chain Liquid Crystalline Polyether in the Crystalline State. 1. Chain Conformation and Dynamics of the Spacer Methylene Sequences
}

\author{
Hiroyuki IshidA, ${ }^{1, \dagger \dagger}$ Yasushi MAEKAwA, ${ }^{1}$ Fumitaka HoRII, ${ }^{1, \dagger}$ and Takashi YAMAMOTO $^{2}$ \\ ${ }^{1}$ Institute for Chemical Research, Kyoto University, Uji, Kyoto 611-0011, Japan \\ ${ }^{2}$ Faculty of Science, Yamaguchi University, Yamaguchi 753-8512, Japan
}

(Received May 2, 2006; Accepted July 4, 2006; Published August 18, 2006)

\begin{abstract}
Molecular dynamics simulations have been performed for the main-chain thermotropic liquid crystalline polyether (EDMB-10), which is composed of the 3,3'-dimethyl-4,4'-biphenylene mesogens and 10-methylene spacers, in order to compare the spacer conformation and dynamics with those revealed by solid-state ${ }^{13} \mathrm{C}$ NMR spectroscopy. A three-dimensional periodic cell that contains 4 or 16 molecular chains composed of four mesogen and five spacer units are employed, the central $\mathrm{CH}_{2}$ sequences of the five spacer sequences being focused on for four chains in the 4-chain model or for the central four chains in the 16-chain model. For both models, the initial structure stays unchanged below $150 \mathrm{~K}$. At $200 \mathrm{~K}$, three dimensional structure begins to change and the molecular arrangement and the cell parameters are finally varied without any significant change in conformation. Below $250 \mathrm{~K}$ the torsion angles of the $\mathrm{O}-\mathrm{CH}_{2}$ bonds at the spacer ends are $\pm 90^{\circ}$ and all the $\mathrm{C}-\mathrm{C}$ bonds adopt the trans conformation for both structural models. At $300 \mathrm{~K}$, the $\mathrm{O}-\mathrm{CH}_{2}$ bond and its second neighboring $\mathrm{C}-\mathrm{C}$ bond are found to undergo the cooperative counter rotation of $\pm 90^{\circ} t t \leftrightarrow t t g^{ \pm}$keep the periodic length between the neighboring mesogen units along the chain almost constant. At $450 \mathrm{~K}$, the $\mathrm{CH}_{2}$ sequences start to adopt a conformational pair of $g^{+} t g^{-}$, which is frequently called the $2 \mathrm{~g} 1$ kink, for the 4-chain model, but the introductions of the kinks are restricted to the alternate four $\mathrm{C}-\mathrm{C}$ bonds. This result is qualitatively in good accord with the result previously obtained for EDMB-10 by the solid-state ${ }^{13} \mathrm{C}$ NMR analysis, but the $t / g$ probabilities at the alternate $\mathrm{C}-\mathrm{C}$ bonds for the simulations significantly disagree with the experimental results. In contrast, for the 16-chain model, a pair of the $g^{+}$and $g^{-}$conformations are allowed to introduce to the alternate four $\mathrm{C}-\mathrm{C}$ bonds at almost equal probabilities without any restriction of the forms of the kinks, resulting in the good qualitative and quantitative agreements with the experimental results. The time evolution of the torsion angles for the respective $\mathrm{C}-\mathrm{C}$ bonds of the spacer $\mathrm{CH}_{2}$ sequences are also described for the 16-chain model to reveal cooperative conformational transitions. [doi:10.1295/polymj.PJ2006023]

KEY WORDS Molecular Dynamics / Computer Simulations / Liquid Crystalline Polymers / Conformation / Spacer Methylene Sequences / Kinks /
\end{abstract}

In previous papers, ${ }^{1-3}$ solid-state ${ }^{13} \mathrm{C}$ NMR analyses of the structure and chain conformation were conducted in detail at room temperature for the main-chain thermotropic liquid crystalline polyether (EDMB-10) which was polymerized from 3,3'-dimethyl-4,4'-dihydroxy biphenyl as a mesogen unit and 1,10-dibromodecane as a spacer $\mathrm{CH}_{2}$ sequence. The sample characterized was crystallized from the melt through the nematic phase appearing at $386-371 \mathrm{~K} .{ }^{1}{ }^{13} \mathrm{C}$ spinlattice relaxation time analyses revealed that the sample contains three components with different molecular mobilities which correspond to the crystalline, medium, and noncrystalline components. Furthermore, the spacer $\mathrm{CH}_{2}$ conformation for each component was evaluated by considering the $\gamma$-gauche effect ${ }^{4}$ on the ${ }^{13} \mathrm{C}$ chemical shifts. As a result, the spacer $\mathrm{CH}_{2}$ sequences were found to adopt the alternate trans $(t)$ and trans-gauche exchange $(x)$ conformation (txtxtxtxt) in the crystalline and medium components. In contrast, all the $\mathrm{C}-\mathrm{C}$ bonds of the noncrystalline component were in the rapid trans-gauche exchange

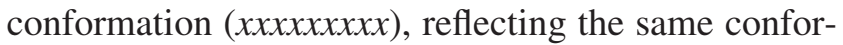
mation in the nematic phase or at the melt.

In this paper, molecular dynamics (MD) simulations are performed for the model crystals of an EDMB-10 oligomer in order to examine whether the spacer $\mathrm{CH}_{2}$ sequences undergo enhanced molecular motions and adopt the same conformation txtxtxtxt as that experimentally observed at room temperature even in the crystalline region where the mesogen units will form the crystal lattice.

\section{STRUCTURAL MODELS AND SIMULATION METHODS}

The MD simulations are carried out by using the

\footnotetext{
${ }^{\dagger}$ To whom correspondence should be addressed (E-mail: horii@scl.kyoto-u.ac.jp).

${ }^{\dagger}$ Present address: Toray Research Center, Otsu 520-0842, Japan
} 
Cerius $^{2}$ (Ver. 4.2 MatSci) software from Molecular Simulations Inc., USA (MSI) with the polymer consistent force field (PCFF), ${ }^{5-16}$ which is the second-generation force field. Two model crystal systems used in this paper are constructed by setting four or sixteen short-chain molecules that are composed of four mesogens and five spacers in an MD cell under the three-dimensional periodic boundary condition. In these cases, the structure and dynamics will be evaluated only for the central spacer $\mathrm{CH}_{2}$ sequences along the respective chains because they may have almost no influence from the chain ends.

The initial structure is first optimized at $100 \mathrm{~K}$ until a minimum energy is obtained for the 4-chain model, as shown in Figure 1a. The repeating period along the molecular chain axis for the optimized structure is $2.077 \mathrm{~nm}$. Since the corresponding repeating period obtained by wide-angle X-ray diffractometry for a uniaxially drawn EDMB-10 sample was $1.933 \mathrm{~nm},{ }^{17}$ these values are almost in accord with each other. (a)
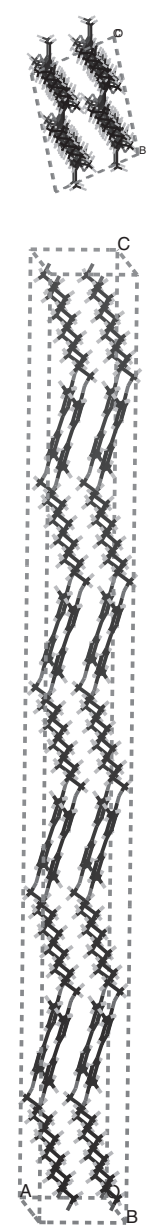

(b)
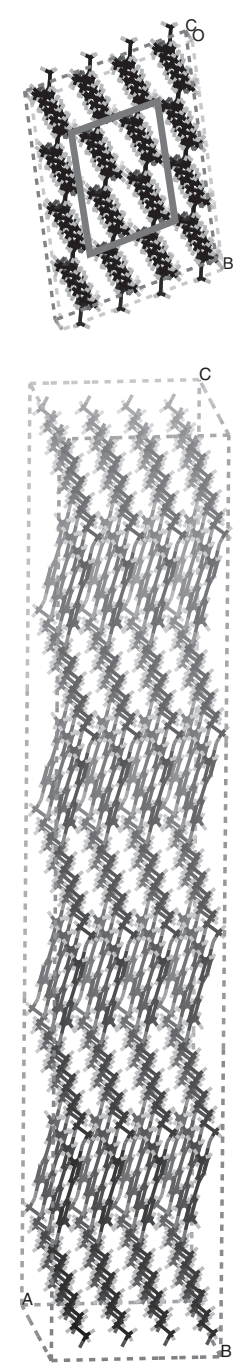

Figure 1. Initial structures of two crystal models: (a) the 4-chain model, (b) the 16-chain model.
Therefore, the optimized structure is utilized as an initial structure for further MD simulations. In the 4-chain model, the laterally periodic boundary condition may produce some restriction to the respective molecules because of the small cell and then the chain conformation and dynamics may be significantly deviated from the actual state. In order to reduce such a restriction, we also prepare the 16-chain model as shown Figure 1b. In the following analysis, we pay our attention only on the central $\mathrm{CH}_{2}$ sequences for the four central chains in the 16 chainmodel for easier comparison with those in the 4-chain model.

The MD simulations were performed on CRAY Origin 2000 as follows: The Verlet leapfrog integrator with a time step of $1 \mathrm{fs}$ and the Nosé-Hoover method $^{18,19}$ for the temperature control were employed to conduct all runs at a constant pressure and temperature (NPT). The simulations were performed at an interval of $50 \mathrm{~K}$ in the temperature range from $100 \mathrm{~K}$ to $500 \mathrm{~K}$. At each temperature, an approximately 200,000-2,000,000 step simulation was executed and the MD trajectories were stored at every $0.1 \mathrm{ps}$. The number of analyzed frames was 2001 at temperatures lower than $250 \mathrm{~K}$ and 4001 at temperatures higher than $300 \mathrm{~K}$.

\section{RESULTS AND DISCUSSION}

\section{Structural Changes with Increasing Temperature}

Figures 2 and 3 show snapshots after 100 ps at various temperatures for the 4-chain and 16-chain models, respectively. In the 16-chain model, only the snapshots for the four central chains are depicted to compare them with those for the 4-chain model. The initial structure is found to stay unchanged at $100 \mathrm{~K}$ and $150 \mathrm{~K}$ in each model, as seen in Figures $2 \mathrm{a}$ and 3a. At $200 \mathrm{~K}$, the three-dimensional structure begins to change; the molecular arrangement and the cell parameters are varied with a lapse of time without any significant change of the conformation. At 350 or $300 \mathrm{~K}$, as respectively shown in Figure $2 \mathrm{c}$ or $3 \mathrm{c}$, evident changes are found to occur in torsion angles for the $\mathrm{O}-\mathrm{CH}_{2}$ and their second neighboring $\mathrm{C}-\mathrm{C}$ bonds for the central spacer $\mathrm{CH}_{2}$ sequence in each molecular chain: the $\mathrm{O}-\mathrm{C} 8$ and $\mathrm{C} 9-\mathrm{C} 10$ bonds really undergo conformational transitions of $\pm 90^{\circ} \leftrightarrow$ trans and trans $\leftrightarrow$ gauche $^{ \pm}$, respectively, as explicitly shown in Figures 4 and 5 later. With the further increase in temperature to $450 \mathrm{~K}$ (Figure $2 \mathrm{~d}$ ) for the 4-chain model and to $400 \mathrm{~K}$ (Figure 3d) for the 16-chain model, the gauche conformations are also introduced to the central part of the spacer $\mathrm{CH}_{2}$ sequences and the plural transitions between trans and gauche are observed for the same $\mathrm{C}-\mathrm{C}$ bonds. In contrast to such changes 
(a)

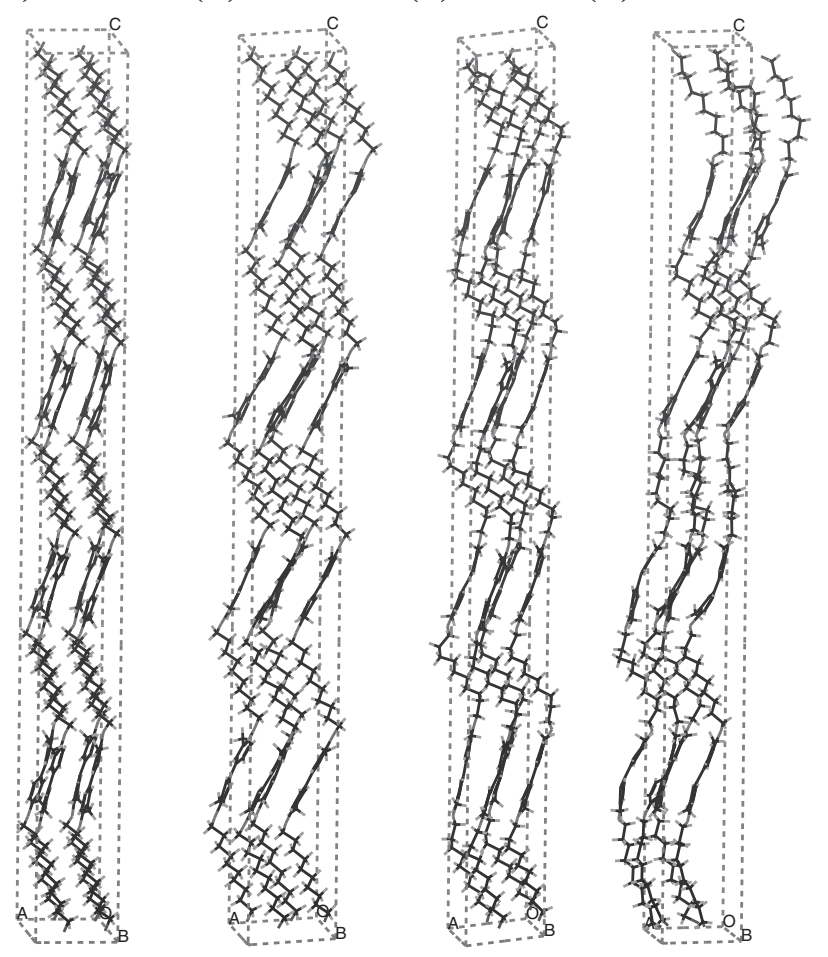

Figure 2. Snapshots for the 4 chains in the 4-chain model at various temperatures: (a) $100 \mathrm{~K}$ and $150 \mathrm{~K}$, (b) $200 \mathrm{~K}$, (c) $350 \mathrm{~K}$, (d) $450 \mathrm{~K}$.

(a)

(b)

(c)

(d)

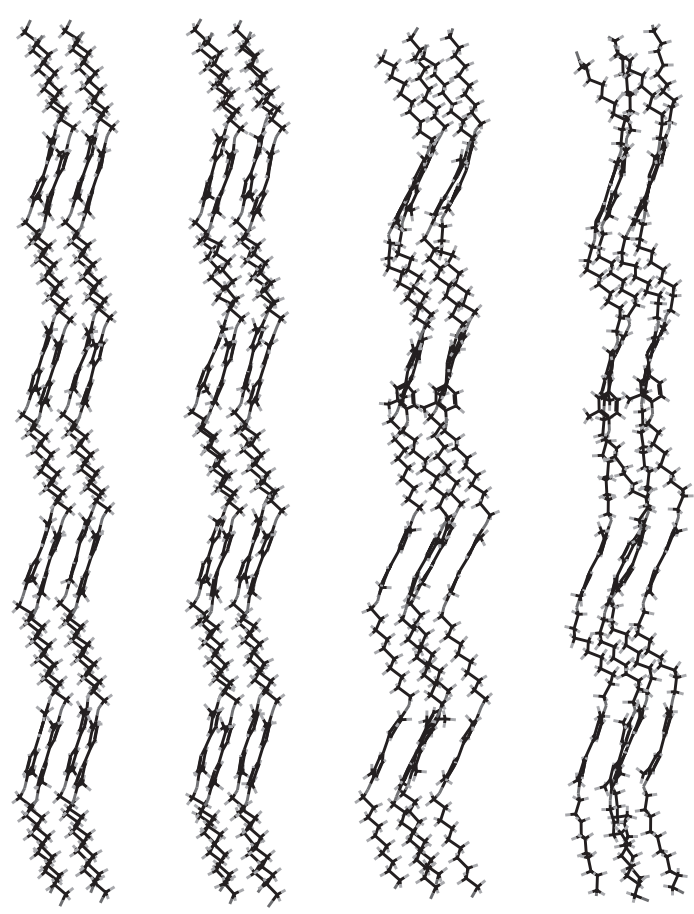

Figure 3. Snapshots for the four central chains in the 16-chain model at different temperatures: (a) $100 \mathrm{~K}$ and $150 \mathrm{~K}$, (b) $200 \mathrm{~K}$, (c) $300 \mathrm{~K}$, (d) $400 \mathrm{~K}$. (a)

$$
\begin{aligned}
& \begin{array}{llllllllll}
8 & 9 & 10 & 11 & 12 & 12^{\prime} & 11^{\prime} & 10^{\prime} & 9^{\prime} & 8^{\prime}
\end{array} \\
& -\mathrm{O}-\mathrm{CH}_{2}-\mathrm{CH}_{2}-\mathrm{CH}_{2}-\mathrm{CH}_{2}-\mathrm{CH}_{2}-\mathrm{CH}_{2}-\mathrm{CH}_{2}-\mathrm{CH}_{2}-\mathrm{CH}_{2}-\mathrm{CH}_{2}-\mathrm{O}- \\
& \begin{array}{lllllllllll}
+90^{\circ} & t & t & t & t & t & t & t & t & t & -90^{\circ}
\end{array}
\end{aligned}
$$

(b)

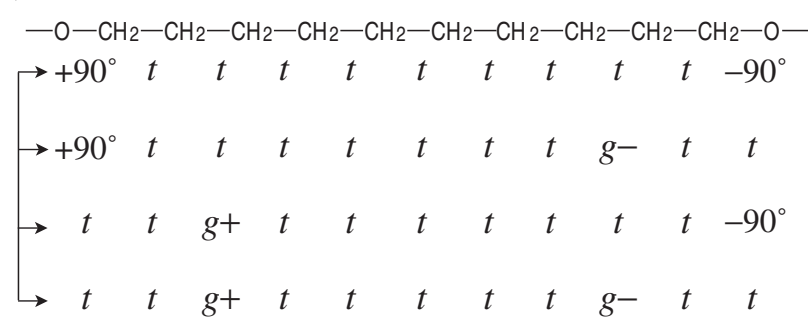

Figure 4. Schematic representations of the conformations of the spacer $\mathrm{CH}_{2}$ sequences for the 4-chain model at different temperatures: (a) $<250 \mathrm{~K}$, (b) $300 \mathrm{~K}$ and $350 \mathrm{~K}$.

(a)

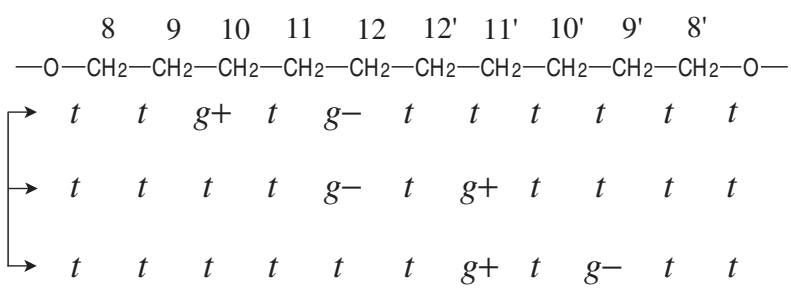

(b)

$-\mathrm{O}-\mathrm{CH}_{2}-\mathrm{CH}_{2}-\mathrm{CH}_{2}-\mathrm{CH}_{2}-\mathrm{CH}_{2}-\mathrm{CH}_{2}-\mathrm{CH}_{2}-\mathrm{CH}_{2}-\mathrm{CH}_{2}-\mathrm{CH}_{2}-\mathrm{O}-$

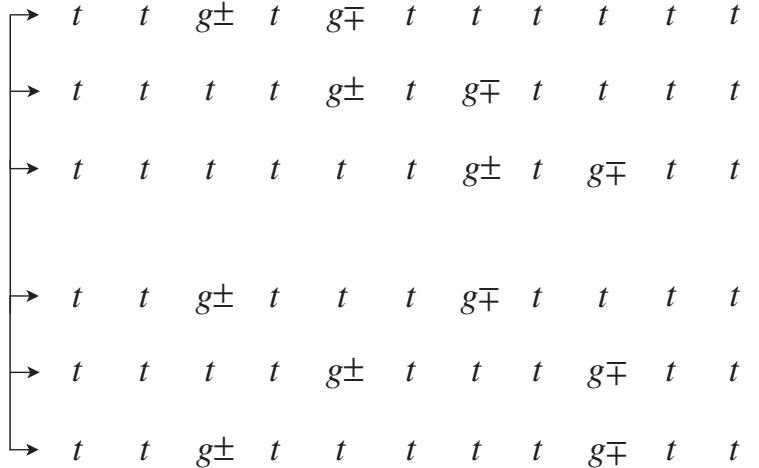

(c)

$$
-\mathrm{O}-\mathrm{CH}_{2}-\mathrm{CH}_{2}-\mathrm{CH}_{2}-\mathrm{CH}_{2}-\mathrm{CH}_{2}-\mathrm{CH}_{2}-\mathrm{CH}_{2}-\mathrm{CH}_{2}-\mathrm{CH}_{2}-\mathrm{CH}_{2}-\mathrm{O}-
$$

Figure 5. Schematic representations of the conformations of the spacer $\mathrm{CH}_{2}$ sequences at $400 \mathrm{~K}$ for the 4-chain model (a) and at $350 \mathrm{~K}$ for the 16-chain model (b). (c) the conformation as revealed for EDMB-10 by the solid-state ${ }^{13} \mathrm{C}$ NMR analyses. ${ }^{1-3}$

in the spacer conformation, each mesogen unit is found to keep the structure forming the crystal lattice basically unaltered, although the co-planarity of the two phenylene rings in each mesogenic unit begins to be appreciably disordered at higher temperatures as described in detail in near future. ${ }^{20}$ 
Detailed Conformational Changes of the Spacer $\mathrm{CH}_{2}$ Sequences

In order to obtain detailed information about conformational changes in each bond in the central $\mathrm{CH}_{2}$ sequences in both models, the torsion angles $\phi$ obtained for each bond at each MD simulation step were classified into three groups, gauche $e^{+}\left(g^{+}\right)$, trans $(t)$, and gauche $^{-}\left(g^{-}\right)$according to values of $0<\phi<$ $120^{\circ}, 120^{\circ}<\phi<240^{\circ}$, and $240^{\circ}<\phi<360^{\circ}$, respectively. Figure 4 shows the possible conformations thus obtained at various temperatures for all the bonds associated with the central $\mathrm{CH}_{2}$ sequences of each molecular chain in the 4-chain model. At temperatures below $250 \mathrm{~K}$, the torsion angles of a pair of $\mathrm{O}-\mathrm{CH}_{2}$ bonds at the ends of the spacer $\mathrm{CH}_{2}$ sequence are $+90^{\circ}$ and $-90^{\circ}$ and all the $\mathrm{C}-\mathrm{C}$ bonds adopt the $t$ conformation for both models, as shown in Figure 4a. Such a structure is kept unchanged at least for $100 \mathrm{ps}$ in the MD simulations, being in accord with the initial structure that was minimized as the most energetically stable structure in the crystal lattice as described above.

At $300 \mathrm{~K}$, for example, the $g^{+}$conformation happens to be introduced in the $\mathrm{C} 9-\mathrm{C} 10$ bond and the torsion angle of the $\mathrm{O}-\mathrm{C} 8$ bond changes from $+90^{\circ}$ to $180^{\circ}(t)$ as a coupled motion as shown in Figure $4 \mathrm{~b}$. Such coupled motions seem to be essential to keep the periodic length between the mesogen units along the molecular chain axis constant even in the case of the introduction of the $g$ conformation. At $350 \mathrm{~K}$, four conformations as shown in Figure $4 \mathrm{~b}$ are allowable but the probability that both of the torsion angles for the $\mathrm{O}-\mathrm{C} 8$ and $\mathrm{C} 8^{\prime}-\mathrm{O}$ bonds maintain $\pm 90^{\circ}$ becomes negligibly small. Moreover, when the two $g$ conformations are introduced to the $\mathrm{CH}_{2}$ sequence, the bonds are also confined to the $\mathrm{C} 9-\mathrm{C} 10$ and $\mathrm{C} 9^{\prime}-$ $\mathrm{C} 10^{\prime}$ bonds and their rotations around the bonds are symmetric as indicated by $g^{+}$and $g^{-}$to keep the molecular chain axis almost unaltered.

With the further increase in temperature to $400 \mathrm{~K}$, the $\mathrm{CH}_{2}$ sequences begin to adopt a conformational pair described as $g^{+} t g^{-}$or $g^{-} t g^{+}$, which is usually referred to as a $2 \mathrm{~g} 1 \mathrm{kink},{ }^{21,22}$ for the 4-chain model as shown in Figure 5a. The bonds to which the $g^{ \pm}$ conformations are introduced are still restricted to the alternate four $\mathrm{C}-\mathrm{C}$ bonds, the $\mathrm{C} 9-\mathrm{C} 10, \mathrm{C} 11-\mathrm{C} 12$, $\mathrm{C} 12^{\prime}-\mathrm{C} 11^{\prime}$, and $\mathrm{C} 10^{\prime}-\mathrm{C} 9^{\prime}$ bonds. These four bonds are in good accord with the bonds that adopt the $t-g$ exchange conformation $(x)$ as shown in Figure 5c, which was experimentally revealed at room temperature in the crystalline region for EDMB-10 by the solid-state ${ }^{13} \mathrm{C}$ NMR analysis. ${ }^{1-3}$ It should be, however, noted that the $g$ conformations are allowed to introduce only as $2 \mathrm{~g} 1$ kinks in these bonds. Therefore, the time aver- aged $t$-g exchange conformation of the three cases shown in Figure 5a for each bond is not described as the $x$ conformation that corresponds to the exchange conformation with equal $t$ and $g$ probabilities; much higher $g$ contributions are observed for the central C11-C12 and C12'-11' bonds in the 4-chain model. Such disagreement with the experimental result shown in Figure 5c may be mainly due to relatively low freedom allowable for the four chains in the cell for the 4-chain model under the periodic boundary condition.

In contrast, similar conformational changes of the spacer $\mathrm{CH}_{2}$ sequences tend to occur at relatively lower temperatures for the 16-chain model. As seen in Figure 5b, about two $g$ conformations are able to be also introduced at $350 \mathrm{~K}$ in the same alternate four $\mathrm{C}-\mathrm{C}$ bonds as for the case shown in Figure 5a. However, there is no restriction of the introduction of the $g$ conformations as $2 \mathrm{~g} 1$ kinks here unlike the case for the 4-chain model: The $g^{+}$or $g^{-}$conformation is allowed to introduce to all possible $\mathrm{C}-\mathrm{C}$ bonds at almost equal probabilities. The only restriction seems to be the introduction of a pair of $g^{+}$and $g^{-}$conformation in the same $\mathrm{CH}_{2}$ sequence as $2 \mathrm{~g} 1,2 \mathrm{~g} 3$, or $2 \mathrm{~g} 5$ kinks, ${ }^{21,22}$ which keeps the molecular chain axis and the periodicity of the mesogen groups almost constant. As a result, the time averaged mole fractions of the $t$ and $g$ conformations for each bond in question are found to be about 0.5 , being in good accord with the experimental result shown in Figure 5c. It is, therefore, concluded that the conformation of the spacer $\mathrm{CH}_{2}$ sequence for EDMB-10 is more realistically described in terms of the 16-chain model.

It should be additionally noted here that the experimental result shown in Figure 5c was obtained at room temperature for the crystalline component and no possible conformational changes of the spacer units have yet been clarified at different temperatures below the melting temperature $(\sim 390 \mathrm{~K})^{1}$ for EDMB10. Moreover, the structure and dynamics of the mesogen units have not been well characterized by both solid-state ${ }^{13} \mathrm{C}$ NMR spectroscopy and MD simulations. ${ }^{2,3,20}$ These indicate that it may be too early to discuss the detailed structure of the spacer units by considering the temperature effects and the phase transition from the crystalline phase to the nematic phase. It should be simply pointed out here that the 16-chain model is more reasonable than the 4-chain model to reproduce the characteristic conformation txtxtxtxt of the spacer units for the crystalline component although the temperature inducing such a conformation seems somewhat higher than the temperature where the solid-state ${ }^{13} \mathrm{C} N M R$ analysis was carried out. 


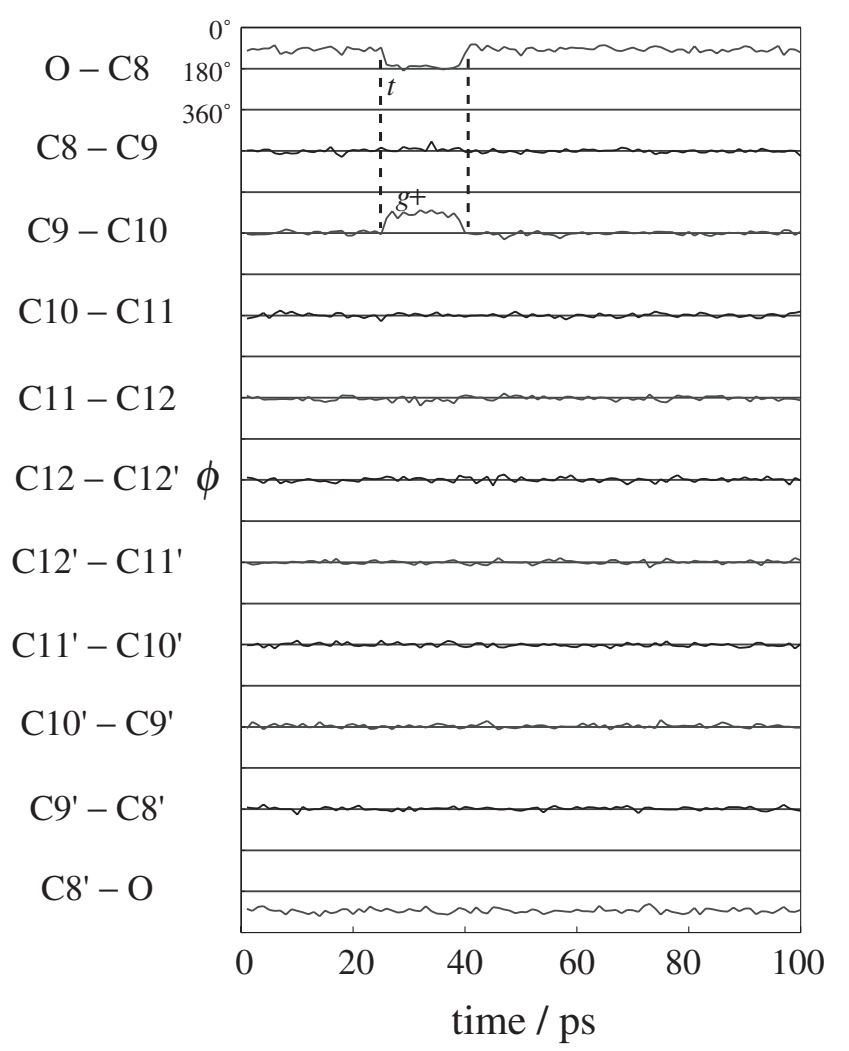

Figure 6. Time evolution for the conformational transitions during $100 \mathrm{ps}$ at $300 \mathrm{~K}$ for the 16-chain model.

\section{Cooperative Conformational Changes Observed in Time Trajectories}

We have also examined the time evolution of the torsion angles for the respective $\mathrm{C}-\mathrm{C}$ bonds of the spacer $\mathrm{CH}_{2}$ sequences at various temperatures in order to investigate cooperative conformational transitions. Figure 6 shows the time trajectories of the torsion angles during $100 \mathrm{ps}$ for the eleven successive bonds of a given spacer in the 16-chain model at $300 \mathrm{~K}$. The conformational changes have been monitored at every $1 \mathrm{ps}$ interval. As described above, the $\mathrm{O}-\mathrm{C} 8$ bond and its second neighboring $\mathrm{C} 9-\mathrm{C} 10$ bond are found to undergo the cooperative conformational change of $90^{\circ} \rightarrow t$ and $t \rightarrow g^{+}$, respectively. At $350 \mathrm{~K}$, such cooperative counter rotations including $-90^{\circ} \rightarrow t$ and $t \rightarrow g^{-}$occurs more frequently in the $\mathrm{C} 8^{\prime}-\mathrm{O}$ and $\mathrm{C} 10^{\prime}-\mathrm{C} 9^{\prime}$ bonds as well as the $\mathrm{O}-\mathrm{C} 8$ and $\mathrm{C} 9-\mathrm{C} 10$ bonds as shown in Figure 7. Moreover, $g^{-}$is also sometimes introduced to the $\mathrm{C} 11-\mathrm{C} 12$ or $\mathrm{C} 12^{\prime}-\mathrm{C} 11^{\prime}$ bond probably as a result of the $g^{-} \rightarrow t$ return change for the $\mathrm{C} 10^{\prime}-\mathrm{C} 9^{\prime}$ bond, keeping the $t$ conformation for the $\mathrm{C} 8^{\prime}-\mathrm{O}$ bond.

Figure 8 shows the time trajectories obtained for the same $\mathrm{CH}_{2}$ sequence in the 16-chain model at $400 \mathrm{~K}$. In a very short time after the simulation starts, the coupled conformational changes as described above are found to occur for the $\mathrm{O}-\mathrm{C} 8 / \mathrm{C} 9-\mathrm{C} 10$ and $\mathrm{C} 8^{\prime}-\mathrm{O} / \mathrm{C} 10^{\prime}-\mathrm{C}^{\prime}$ bond pairs, while the other bonds

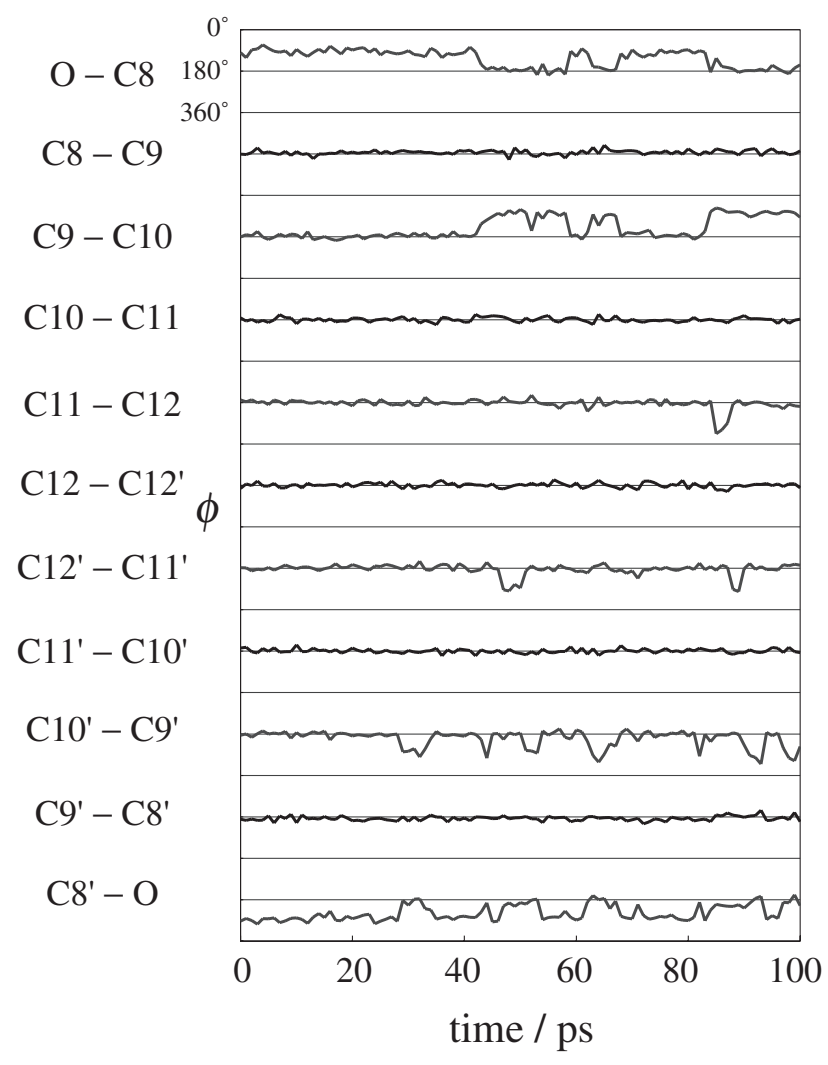

Figure 7. Time evolution for the conformational transitions during $100 \mathrm{ps}$ at $350 \mathrm{~K}$ for the 16 -chain model.

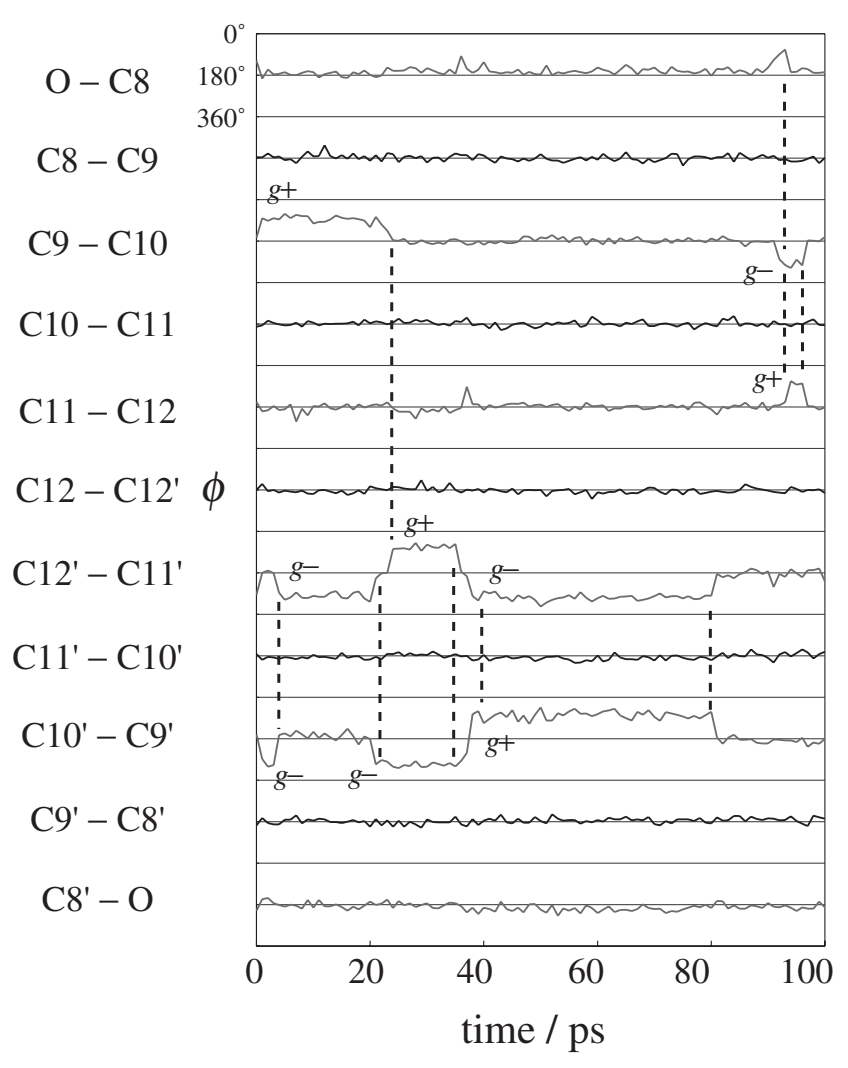

Figure 8. Time evolution for the conformational transitions during $100 \mathrm{ps}$ at $400 \mathrm{~K}$ for the 16-chain model. 
remain in the most stable states allowable at lower temperatures as described above. In a few ps other cooperative conformational changes also occur for the $\mathrm{C} 10^{\prime}-\mathrm{C} 9^{\prime}$ and $\mathrm{C} 12^{\prime}-\mathrm{C} 11^{\prime}$ bonds; $g^{-} \rightarrow t$ and $t \rightarrow g^{-}$, respectively. After about $20 \mathrm{ps}$, the return transitions are observed for these bonds and, moreover, the successive transition of the $t \rightarrow g^{+}$in the $\mathrm{C} 12^{\prime}-\mathrm{C} 11^{\prime}$ bond really seems to induce the $g^{+} \rightarrow t$ return transition for the C9-C10 bond. Nevertheless, most of the transitions in the $\mathrm{C} 10^{\prime}-\mathrm{C} 9^{\prime}$ and $\mathrm{C} 12^{\prime}-\mathrm{C} 11^{\prime}$ bonds are cooperative while the changes seem to be independent in the C9-C10 bond. This fact indicates that most cooperative conformational changes are induced in the second-neighboring $\mathrm{C}-\mathrm{C}$ bonds at $400 \mathrm{~K}$. Such a restriction in the cooperative motion is significantly reduced with increasing temperature; the cooperative transitions are allowable for the alternative $\mathrm{C}-\mathrm{C}$ bonds almost randomly at higher temperatures. In addition, the $t \rightarrow g$ or $g \rightarrow t$ transition rate is estimated to be about $10^{11} \mathrm{~s}^{-1}$ at $400 \mathrm{~K}$ on the basis of the results shown in Figure 7.

Finally, it should be pointed out that the cooperative conformational transitions of the respective $\mathrm{CH}_{2}$ sequences as shown in Figures 6-8 were found to occur incidentally for the respective sequences by the careful examination of the time trajectories. Namely, no further coupling of the cooperative transitions was observed among the central four $\mathrm{CH}_{2}$ sequences in both 4-chain and 16-chain models. Similar structural analyses of the mesogen units including the characterization of the co-planarity of the phenylene rings are also reported somewhere in near future.

\section{CONCLUSIONS}

The conformation and dynamics for the liquid crystalline polyether EDMB-10 have been examined by molecular dynamics simulations and the following conclusions have been obtained.

(1) For both 4-chain model and 16-chain model, which respectively contain 4 and 16 short-chain molecules composed of four mesogen and five spacer units in a three-dimensional periodic cell, the initial structure stays unchanged below $150 \mathrm{~K}$. Here, the central $\mathrm{CH}_{2}$ sequences of the five sequences are focused on in this work for four chains in the 4-chain model or for the four central chains in the 16-chain model. At $200 \mathrm{~K}$, the molecular packing and the cell parameters are significantly altered without the change of the spacer conformation. Above $300 \mathrm{~K}$ the $g$ conformations are introduced to the spacer $\mathrm{CH}_{2}$ sequences, while the mesogen units are found to basically keep the original structure forming the crystal lattice.

(2) In the temperature region from $100 \mathrm{~K}$ to $250 \mathrm{~K}$ the torsion angles of the $\mathrm{O}-\mathrm{CH}_{2}$ bonds at each $\mathrm{CH}_{2}$ sequence are $\pm 90^{\circ}$ and all the $\mathrm{C}-\mathrm{C}$ bonds adopt the $t$ conformation. Over $300 \mathrm{~K}$, the $\mathrm{O}-\mathrm{CH}_{2}$ bonds at the spacer ends undergo conformational changes from $\pm 90^{\circ}$ to $180^{\circ}$ and their second neighboring $\mathrm{C}-\mathrm{C}$ bonds are cooperatively subjected to counter transitions from $t$ to $g^{ \pm}$probably to keep the periodic length between the neighboring mesogen units almost constant. At $400 \mathrm{~K}$ for the 4-chain model or at $350 \mathrm{~K}$ for the 16-chain model, the $g$ conformations are also introduced to the central parts of the spacer $\mathrm{CH}_{2}$ sequences and the positions are restricted to the alternate four $\mathrm{C}-\mathrm{C}$ bonds along each $\mathrm{CH}_{2}$ sequence. However, the $g$ conformations are introduced as $2 \mathrm{~g} 1$ kinks, described by $g^{+} t g^{-}$or $g^{-} t g^{+}$, for the 4-chain model, whereas there is no such restriction for the 16-chain model except for the pair introduction of $g^{+}$and $g^{-}$ along each sequence. As a result, it is found that the 16-chain model allows to well describe the $t$ and $t$ - $g$ exchange conformation for the $\mathrm{CH}_{2}$ sequences previously revealed for the crystalline component in EDMB-10 by the solid-state ${ }^{13} \mathrm{C}$ NMR analysis.

(3) The evaluation of the time evolution of the torsion angles for the respective $\mathrm{C}-\mathrm{C}$ bonds of the spacer $\mathrm{CH}_{2}$ sequences has also revealed the respective cooperative conformational transitions and their average rates for the $\mathrm{CH}_{2}$ sequences in the 16 -chain model at various temperatures.

Acknowledgment. This work was supported by Grant-in-Aid for Scientific Research (No. 12450384) from the Ministry of Education, Culture, Sports, Science and Technology, Japan. Computation time for the MD simulations in this work was provided by the Bioinformatics Center, Institute for Chemical Research, Kyoto University.

\section{REFERENCES}

1. H. Ishida and F. Horii, Macromolecules, 34, 7751 (2001).

2. M. Murakami, H. Ishida, M. Miyazaki, H. Kaji, and F. Horii, Macromolecules, 36, 4160 (2003).

3. M. Murakami, H. Ishida, H. Kaji, and F. Horii, Polym. J., 36, 403 (2004).

4. A. E. Tonelli, "NMR Spectroscopy and Polymer Microstructure: The Conformational Connection," VCH Publishers: New York, 1989.

5. S. Lifson, A. T. Hagler, and P. Dauber, J. Am. Chem. Soc., 101, 5111 (1979).

6. A. T. Hagler, S. Lifson, and P. Dauber, J. Am. Chem. Soc., 101, 5122 (1979).

7. A. T. Hagler, P. Dauber, and S. Lifson, J. Am. Chem. Soc., 101, 5131 (1979).

8. J. R. Maple, U. Dinur, and A. T. Hagler, Proc. Natl. Acad. Sci. U.S.A., 85, 5350 (1988).

9. H. Sun, S. J. Mumby, J. R. Maple, and A. T. Hagler, J. Am. Chem. Soc., 116, 2978 (1994). 
10. H. Sun, S. J. Mumby, J. R. Maple, and A. T. Hagler, J. Phys. Chem., 99, 5873 (1995).

11. H. Sun, Macromolecules, 26, 5924 (1993).

12. H. Sun, Macromolecules, 28, 701 (1995).

13. J. R. Maple, M.-J. Hwang, T. P. Stockfisch, U. Dinur, M. Waldman, C. S. Ewig, and A. T. Hagler, J. Comput. Chem., 15, 162 (1994).

14. H. Sun, J. Comput. Chem., 15, 752 (1994).

15. M.-J. Hwang, T. P. Stockfisch, and A. T. Hagler, J. Am. Chem. Soc., 116, 2515 (1994).

16. J. R. Maple, M.-J. Hwang, T. P. Stockfisch, and A. T.
Hagler, Isr. J. Chem., 34, 195 (1994).

17. M. Ohyama, T. Yamamoto, K. Nozaki, H. Ishida, and F. Horii, Polym. Prepr., Jpn., 52, 2581 (2003).

18. S. Nosé, J. Chem. Phys., 81, 511 (1984).

19. W. Hoover, Phys. Rev. A: At., Mol., Opt. Phys., 31, 1695 (1985).

20. H. Ishida, Y. Maekawa, F. Horii, and T. Yamamoto, Polym. Prepr., Jpn., 52, 433 (2003).

21. B. Wunderlich, "Macromolecular Physics," Academic Press, 1973.

22. W. Pechold, Kolloid Z. Z. Polymere, 228, 1 (1968). 